12 Boehme CC, Nicol MP, Nabeta P, et al. Feasibility, diagnostic accuracy, and effectiveness of decentralised use of the Xpert MTB/RIF test for diagnosis of tuberculosis and multidrug resistance: a multicentre implementation study. Lancet 2011; 377: 1495-1505.

13 Schmit KM, Coeytaux RR, Goode AP, et al. Evaluating cough assessment tools: a systematic review. Chest 2013; 144: $1819-1826$

14 Breen RA, Leonard O, Perrin FM, et al. How good are systemic symptoms and blood inflammatory markers at detecting individuals with tuberculosis? Int J Tuberc Lung Dis 2008; 12: 44-49.

15 Turner RD, Bothamley GH. Cough and the Transmission of Tuberculosis. J Infect Dis 2015; 211 : 1367-1372.

\title{
Ertapenem in the treatment of multidrug-resistant tuberculosis: first clinical experience
}

To the Editor:

Treatment of multidrug-resistant (MDR) tuberculosis (TB) (defined as resistance to at least isoniazid and rifampicin, two core first-line drugs for TB treatment) and extensively drug-resistant (XDR)-TB (defined as resistance to isoniazid and rifampicin plus any fluoroquinolone and at least one of the injectable drugs amikacin, capreomycin or kanamycin) are a challenge for both clinicians and public health specialists [1-5]. Treatment outcomes of difficult-to-treat MDR-TB cases (e.g. those with an extensive resistance pattern) are still unsatisfactory, adverse events frequent and severe, and the necessary drugs expensive [6].

A previous proof-of-concept study from our group has suggested that meropenem clavulanate is potentially useful in the treatment of these cases and is also well tolerated [7]. In vitro and pharmacological data suggest that ertapenem, a newer carbapenem compound, is potentially active against Mycobacterium tuberculosis, its longer half-life allowing single daily parenteral administration (rather than thrice-daily administration of meropenem) and advantageous homecare or day-hospital management $[8,9]$.

Clinical information necessary to study safety, tolerability and efficacy of ertapenem was retrospectively collected on all MDR-TB cases treated at the E. Morelli Hospital (the TB reference centre for Italy) between 2008 and 2015. Carbapenems were used in MDR-TB patients lacking active drugs in their regimen. Meropenem ( $3 \mathrm{~g}$ three times daily) or imipenem (500 $\mathrm{mg}$ four times a day) was given during hospital stay and if limited drug options switched to ertapenem ( $1 \mathrm{~g}$ once daily) for easier home-care or day-hospital administration.

Regimens to treat MDR/XDR-TB cases were tailored to drug susceptibility testing (DST) results according to World Health Organization (WHO) recommendations [2] to design an Optimised Background Regimen (OBR), using fluoroquinolones, injectable agents and other second-line oral agents co-administered with linezolid and carbapenems in heavily resistant/drug-intolerant individuals. A team composed of three external investigators reviewed and agreed on each clinical record reporting on the use of carbapenems in the study period, in collaboration with local specialists.

The database was developed to be consistent with that used in previous studies $[7,10,11]$. The protocol and outcome definitions were compatible with those used to study the largest MDR-TB cohort available [3, 4].

A patient who completed treatment as recommended by the national policy without evidence of failure and was consistently culture-negative with at least three or more consecutive cultures taken at least 30 days apart after the intensive phase was defined as cured. Treatment failure was defined as treatment terminated or need for a permanent regimen change of at least two anti-TB drugs because of: 1) lack of conversion by the end of the intensive phase; 2 ) bacteriological reversion in the continuation phase after conversion to negative; 3 ) evidence of additional acquired resistance to fluoroquinolones or second-line injectable drugs; or 4) adverse drug reactions [1].

Sputum conversion was defined as two consecutive negative sputum smears in patients who were sputum smear-positive at diagnosis. Time to culture conversion was defined as time from treatment start to the date of the first of two consecutive negative cultures $[7,10]$. 
Approval for collection of study data was provided by the ethical committee of the coordinating centre in Tradate, Italy $[7,10,11]$, in compliance with national regulations and organisational requirements for protection of human subjects. All data were coded and individual identifiers were available only to treating physicians.

Safety and tolerability outcomes included major and minor adverse events. Any adverse reaction resulting in temporary or permanent discontinuation of a drug was defined as major, while a minor adverse event required only dose adjustment and/or addition of concomitant treatment [7, 10]. Efficacy end-points included time to sputum smear and culture conversions, and treatment outcomes $[7,10]$.

DST for all first- and second-line anti-TB drugs was performed by the Reference Laboratory in Sondalo, Italy, which participates in the WHO-approved external quality-assured programme $[1,2,7,10]$. In Sondalo, sputum smear examinations are performed weekly until negative and then monthly. Cultures are performed monthly $[7,10]$.

The main results are summarised in table 1. Five cases (two females and three males) of pulmonary TB with a mean age of 35.5 years were treated with ertapenem. All were HIV seronegative, previously treated for TB for $>30$ days (average 2.5 times) and reporting treatment failure. At diagnosis, the cases were sputum smear and culture positive with bilateral cavities on chest radiography. Resistance patterns were severe, with documented resistance to at least four out of the five first-line drugs and to several core second-line anti-TB drugs (average 9.2 resistances per case). Two cases were XDR and three pre-XDR (e.g. either resistance to fluoroquinolones (one case) or to second-line injectables (two cases)), as clinicians are used to calling them. Four cases were immigrants from countries with high MDR-TB prevalence (Moldova, Romania and Ukraine).

Three cases achieved cure, one completed treatment without meeting the criteria for cure (no expectoration), and one failed to convert his sputum smear and culture, and died after 114 days of hospital admission. Meropenem or imipenem exposure was, on average, 34.4 days (table 1), while that of ertapenem was 431.4 days (median 540 days, range 20-690 days). The average exposure to linezolid was 590.5 days at the mean dose of $975 \mathrm{mg} \cdot \mathrm{day}^{-1}$ (with a single, minor, gastrointestinal adverse event described in case 4). The adoption of TDM (Therapeutic Drug Monitoring) allowed optimisation of the dose and reduction of the adverse events with this drug $[11,12]$.

All carbapenem drugs were well tolerated and never required interruption or dose adjustment. Of note, due to its complexity, case 1 required bedaquiline (under compassionate use) to ensure a sufficient number of active drugs [13].

In the three out of five patients converting and for whom a time to bacteriological conversion was available (patient 2 died shortly within a month of the start of treatment and patient 3 did not expectorate after discharge), the average time to achieve bacteriological conversion was 47.7 days for sputum smear and 60 days for culture.

This study represents the first clinical report, to our knowledge, on the use of ertapenem to treat MDRand XDR-TB, with the specific role of simplifying the administration of the carbapenem when the patient is at home. The small sample size and the retrospective nature of the study limit the possibility of generalising its results. However, the good tolerability and the positive outcomes achieved in the majority of the cases suggest continuing studying the clinical potential of carbapenems against MDR- and XDR-TB. With this in mind, an international consortium, ECSG (European Carbapenems Study Group), was created to further study meropenem, imipenem and ertapenem, and to investigate their role when added to OBR to treat MDR- and XDR-TB cases.

The clinical management of these cases is extremely expensive. Diel et al. [6] estimated a cost, in Europe, of $€ 6466124$ to treat $136 \mathrm{XDR}-\mathrm{TB}$ cases, which is equivalent to $€ 88.05$ per day just to purchase drugs. The cost is very conservative. In fact, the long exposure to both linezolid and carbapenems (plus bedaquiline in case 1) in these extremely severe cases generated very high costs for drugs, to be added to the other costs related to hospital stay (on the order of 100 days per case).

The time necessary to achieve bacteriological conversion is long, and a portion of these cases (one out of five in our study), unfortunately, remain infectious till death. Although the absolute numbers are small $[1,6]$, even low TB incidence countries continue to face almost untreatable TB cases [14] without necessarily having the capacity to prevent secondary infections and, therefore, future cases sustained by potentially lethal strains [15].

A coordinated action is necessary at the European level to strengthen public health services (within National TB Programmes, where still in place) to prevent MDR-TB, while continuing the search for new drugs and the research on the potentialities of existing molecules with proven activity against M. tuberculosis. 
TABLE 1 Clinical characteristics of five patients with multidrug-resistant/extensively drug-resistant tuberculosis (TB) treated with ertapenem in Sondalo, Italy

\begin{tabular}{|c|c|c|c|c|c|c|c|c|c|c|c|c|c|c|}
\hline Patient & $\begin{array}{l}\text { Age } \\
\text { years }\end{array}$ & Sex & $\begin{array}{l}\text { Country } \\
\text { of birth }\end{array}$ & $\begin{array}{c}\text { Previous } \\
\text { exposure } \\
\text { to anti-TB } \\
\text { therapy } \\
>30 \text { days }\end{array}$ & $\begin{array}{c}\text { Total } \\
\text { hospital } \\
\text { admission } \\
\text { time days }\end{array}$ & $\begin{array}{l}\text { Drug } \\
\text { resistance } \\
\text { profile }\end{array}$ & $\begin{array}{l}\text { Anti-TB } \\
\text { regimen }\end{array}$ & $\begin{array}{l}\text { Sputum smear } \\
\text { conversion } \\
\text { time days }\end{array}$ & $\begin{array}{l}\text { Sputum } \\
\text { culture } \\
\text { conversion } \\
\text { time days }\end{array}$ & $\begin{array}{c}\text { Lzd } \\
\text { exposure } \\
\text { time } \\
\text { days/daily } \\
\text { dose } \mathrm{mg}\end{array}$ & $\begin{array}{c}\text { Carbapenem } \\
\text { exposure } \\
\text { days/daily } \\
\text { dose } \mathrm{mg}\end{array}$ & $\begin{array}{c}\text { Erta } \\
\text { exposure } \\
\text { days/daily } \\
\text { dose } \mathbf{g}\end{array}$ & $\begin{array}{l}\text { Adverse } \\
\text { events }\end{array}$ & Outcome \\
\hline 1 & 35 & $\mathrm{~F}$ & Ukraine & 3 & 128 & $\begin{array}{l}\text { H, R, E, Z, S, FQ, } \\
\text { Eto, Amk, Cm, Km }\end{array}$ & $\begin{array}{c}\text { Amx/Clv, Cfz, Trd, } \\
\text { Mero/Erta, Eto, } \\
\text { Bdq, Lzd, Mfx }\end{array}$ & 62 & 88 & $730 / 900$ & Mero 91/3 & $248 / 1$ & No & Cured \\
\hline 2 & 33 & M & Moldova & 2 & 114 & $\begin{array}{l}\mathrm{H}, \mathrm{R}, \mathrm{E}, \mathrm{S}, \mathrm{FQ}, \text { Eto, } \\
\text { Trd, Amk, PAS, Km }\end{array}$ & $\begin{array}{c}\mathrm{Cm} \text {, Ipm/Cln-Erta, } \\
\text { Mfx, PAS, Eto }\end{array}$ & Not achieved & Not achieved & No & Ipm 5/2 & $20 / 1$ & No & $\begin{array}{l}\text { Bacteriologically } \\
\text { positive till death }\end{array}$ \\
\hline 3 & 23 & M & Moldova & 2 & 53 & $\begin{array}{l}\text { H, R, E, Z, S, Eto, } \\
\text { Trd, Amk, PAS, Km }\end{array}$ & $\begin{array}{c}\text { Amk, E, Ipm/ } \\
\text { Cln-Erta, Lzd, Mfx }\end{array}$ & $\begin{array}{l}\text { Sputum } \\
\text { positive at } \\
\text { discharge } \\
\text { No longer } \\
\text { expectorating } \\
\text { at the } \\
\text { following } \\
\text { controls }\end{array}$ & $\begin{array}{l}\text { Culture } \\
\text { positive at } \\
\text { discharge } \\
\text { No longer } \\
\text { expectorating } \\
\text { at the } \\
\text { following } \\
\text { controls }\end{array}$ & $182 / 1200$ & Ipm 3/2 & $540 / 1$ & No & $\begin{array}{l}\text { Alive, improved, } \\
\text { treatment } \\
\text { completed as no } \\
\text { formal evidence } \\
\text { of negative } \\
\text { cultures }\end{array}$ \\
\hline 4 & 51 & M & Italy & 3 & 110 & $\begin{array}{l}\text { H, R, E, Z, S, Eto, } \\
\text { Trd, Amk, PAS, Km }\end{array}$ & $\begin{array}{l}\text { Amk, Trd, Ipm/Cln, } \\
\text { Erta, Lzd, Mfx, Eto }\end{array}$ & 21 & 39 & $720 / 1200$ & Ipm 2/2 & $690 / 1$ & $\begin{array}{l}\text { Gastrointestinal, } \\
\text { transient (Lzd } \\
\text { restarted) }\end{array}$ & Cured \\
\hline 5 & 30 & $\mathrm{~F}$ & Romania & 1 & 104 & $\mathrm{H}, \mathrm{R}, \mathrm{Z}, \mathrm{S}, \mathrm{FQ}$, Eto & $\begin{array}{c}\text { Amk, Trd, E, } \\
\text { Mero/Erta, Amx/ } \\
\text { Clv, Lzd, Mfx, PAS }\end{array}$ & 60 & 53 & $730 / 600$ & Mero 71/3 & $659 / 1$ & $\begin{array}{l}\text { Gastrointestinal, } \\
\text { transient (PAS } \\
\text { restarted) }\end{array}$ & Cured \\
\hline Average & 35.5 & & & 2.5 & 96.7 & 9.2 drugs & $\begin{array}{c}6.4 \text { drugs } \\
\text { (5.6 active) }\end{array}$ & 47.7 & 60 & 590.5 & 34.4 & 431.4 & & \\
\hline
\end{tabular}

The first-line anti-TB drugs: group 1 (oral: isoniazid (H), rifampicin (R), pyrazinamide (Z), ethambutol (E), rifapentine and rifabutin). Second-line anti-TB drugs: group 2 (injectable aminoglycosides: streptomycin (S), kanamycin ( $\mathrm{Km}$ ) and amikacin (Amk); injectable polypeptides: capreomycin (Cm) and viomycin); group 3 (oral and injectable fluoroquinolones: ciprofloxacin, levofloxacin, moxifloxacin (Mfx), ofloxacin and gatifloxacin); group 4 (oral: para-aminosalicylic acid (PAS), cycloserine, terizidone (Trd), ethionamide (Eto), prothionamide, thioacetazone and linezolid (Lzd). Third-line anti-TB drugs: group 5 (clofazimine (Cfz), Lzd, amoxicillin plus clavulanate (Amx/Clv), imipenem plus cilastatin (Ipm/Cln), clarithromycin and bedaquiline (Bdq)). F: female; M: male; FQ: fluoroquinolone; Mero: meropenem; Erta: ertapenem. 

patient is at home http://ow.ly/Snx69

Simon Tiberi ${ }^{1,7}$, Lia D’Ambrosio ${ }^{2,3,7}$, Saverio De Lorenzo ${ }^{4,7}$, Pietro Viggiani ${ }^{4}$, Rosella Centis ${ }^{3}$, Giovanni Sotgiu ${ }^{5}$, Jan Wilem C. Alffenaar ${ }^{6}$ and Giovanni Battista Migliori $^{3}$

${ }^{1}$ Division of Infection, Barts Healthcare NHS Trust, London, UK. ${ }^{2}$ Public Health Consulting Group, Lugano, Switzerland. ${ }^{3}$ WHO Collaborating Centre for TB and Lung Diseases, Fondazione S. Maugeri, Tradate, Italy. ${ }^{4}$ Eugenio Morelli MDR-TB Reference Hospital, AOVV, Sondalo, Italy. ${ }^{5}$ Clinical Epidemiology and Medical Statistics Unit, Dept of Biomedical Sciences, University of Sassari - Research, Medical Education and Professional Development Unit, AOU Sassari, Sassari, Italy. ${ }^{6}$ University of Groningen, University Medical Center Groningen, Dept of Clinical Pharmacy and Pharmacology, Groningen, The Netherlands. ${ }^{7}$ These authors contributed equally.

Correspondence: Giovanni Battista Migliori, WHO Collaborating Centre for TB and Lung Diseases, Fondazione S. Maugeri, Via Roncaccio 16, Tradate, Varese 21049, Italy. E-mail: giovannibattista.migliori@fsm.it

Received: Aug 032015 | Accepted after revision: Aug 262015 | First published online: Nov 192015

Conflict of interest: None declared.

\section{References}

1 World Health Organization. Global tuberculosis report 2014. WHO/HTM/TB2014.08. Geneva, World Health Organization, 2014.

2 Falzon D, Jaramillo E, Schünemann HJ, et al. WHO guidelines for the programmatic management of drug-resistant tuberculosis: 2011 update. Eur Respir J 2011; 38: 516-528.

3 Falzon D, Gandhi N, Migliori GB, et al. Resistance to fluoroquinolones and second-line injectable drugs: impact on multidrug-resistant TB outcomes. Eur Respir J 2013; 42: 156-168.

4 Migliori GB, Sotgiu G, Gandhi NR, et al. Drug resistance beyond extensively drug-resistant tuberculosis: individual patient data meta-analysis. Eur Respir J 2013; 42: 169-179.

5 Blasi F, Dara M, van der Werf MJ, et al. Supporting TB clinicians managing difficult cases: the ERS/WHO Consilium. Eur Respir J 2013; 41: 491-494.

6 Diel R, Vandeputte J, de Vries G, et al. Costs of tuberculosis disease in the European Union: a systematic analysis and cost calculation. Eur Respir J 2014; 43: 554-565.

7 De Lorenzo S, Alffenaar JW, Sotgiu G, et al. Efficacy and safety of meropenem-clavulanate added to linezolid-containing regimens in the treatment of MDR-/XDR-TB. Eur Respir J 2013; 41: 1386-1392.

8 Cordillot M, Dubée V, Triboulet S, et al. In vitro cross-linking of Mycobacterium tuberculosis peptidoglycan by L,D-transpeptidases and inactivation of these enzymes by carbapenems. Antimicrob Agents Chemother 2013; 57: 5940-5945.

9 Tremblay LW, Fan F, Blanchard JS. Biochemical and structural characterization of Mycobacterium tuberculosis beta-lactamase with the carbapenems ertapenem and doripenem. Biochemistry 2010; 49: 3766-3773.

10 De Lorenzo S, Centis R, D’Ambrosio L, et al. On linezolid efficacy and tolerability. Eur Respir J 2012; 39: 770-772.

11 Sotgiu G, Centis R, D'Ambrosio L, et al. Efficacy, safety and tolerability of linezolid containing regimens in treating MDR-TB and XDR-TB: systematic review and meta-analysis. Eur Respir J 2012; 40: 1430-1442.

12 Srivastava S, Peloquin CA, Sotgiu G, et al. Therapeutic drug management: is it the future of multidrug-resistant tuberculosis treatment? Eur Respir J 2013; 42: 1449-1453.

13 Tiberi S, De Lorenzo S, Centis R, et al. Bedaquiline in MDR/XDR-TB cases: first experience on compassionate use. Eur Respir J 2014; 43: 289-292.

14 Esposito S, D'Ambrosio L, Tadolini M, et al. ERS/WHO Tuberculosis Consilium assistance with extensively drug-resistant tuberculosis management in a child: case study of compassionate delamanid use. Eur Respir J 2014; 44: 811-815.

15 Sotgiu G, D'Ambrosio L, Centis R, et al. TB and M/XDR-TB infection control in European TB reference centres: the Achilles' heel? Eur Respir J 2011; 38: 1221-1223.

\section{Restrictive chronic lung function decline after haematopoietic stem cell transplantation}

To the Editor:

Until recently, it was generally thought that bronchiolitis obliterans syndrome (BOS), which is a type of obstructive lung disease with a dismal outcome, was the sole form of chronic lung allograft dysfunction 